\title{
Receipt of Cancer Screening Is a Predictor of Life Expectancy
}

\author{
James S. Goodwin, MD ${ }^{1,2,3}$, Kristin Sheffield, $P H D^{3,4,5}$, Shuang Li, $P h D^{2}$, and Alai Tan, MD, $P h D^{1,2,3,6}$ \\ 'Department of Internal Medicine, University of Texas Medical Branch, Galveston, TX, USA; ${ }^{2}$ Sealy Center on Aging, University of Texas Medical \\ Branch, Galveston, TX, USA; ${ }^{3}$ Institute for Translational Sciences, University of Texas Medical Branch, Galveston, TX, USA; ${ }^{4}$ Department of Preventive \\ Medicine and Community Health, University of Texas Medical Branch, Galveston, TX, USA; ${ }^{5}$ Global Patient Outcomes and Real World Evidence, Eli \\ Lilly and Company, Indianapolis, IN, USA; ${ }^{6}$ Ohio State University School of Nursing, Columbus, OH, USA.
}

BACKGROUND: Obtaining cancer screening on patients with limited life expectancy has been proposed as a measure for low quality care for primary care physicians (PCPs). However, administrative data may underestimate life expectancy in patients who undergo screening.

OBJECTIVE: To determine the association between receipt of screening mammography or PSA and overall survival.

DESIGN: Retrospective cohort study from 1/1/1999 to $12 / 31 / 2012$. Receipt of screening was assessed for 2001-2002 and survival from 1/1/2003 to 12/31/2012. Life expectancy was estimated as of 1/1/03 using a validated algorithm, and was compared to actual survival for men and women, stratified by receipt of cancer screening. PARTICIPANTS: A 5 \% sample of Medicare beneficiaries aged 69-90 years as of $1 / 1 / 2003(n=906,723)$.

INTERVENTIONS: Receipt of screening mammography in 2001-2002 for women, or a screening PSA test in 2002 for men.

MAIN MEASURES: Survival from 1/1/2003 through 12/ $31 / 2012$.

KEY RESULTS: Subjects were stratified by life expectancy based on age and comorbidity. Within each stratum, the subjects with prior cancer screening had actual median survivals higher than those who were not screened, with differences ranging from 1.7 to 2.1 years for women and 0.9 to 1.1 years for men. In a Cox model, non-receipt of screening in women had an impact on survival (HR= 1.52; $95 \% \mathrm{CI}=1.51,1.54$ ) similar in magnitude to a diagnosis of complicated diabetes or heart failure, and was comparable to uncomplicated diabetes or liver disease in men ( $\mathrm{HR}=1.23 ; 1.22,1.25)$.

CONCLUSIONS: Receipt of cancer screening is a powerful marker of health status that is not captured by comorbidity measures in administrative data. Because life expectancy algorithms using administrative data underestimate the life expectancy of patients who undergo screening, they can overestimate the problem of cancer screening in patients with limited life expectancy.

KEY WORDS: cancer; screening; life expectancy.

J Gen Intern Med 31(11):1308-14

DOI: $10.1007 / \mathrm{s} 11606-016-3787-y$

(C) Society of General Internal Medicine 2016

Received February 1, 2016

Revised May 26, 2016

Accepted June 15, 2016

Published online June 30, 2016

\section{INTRODUCTION}

Over the past few years there has been growing concern about the potential harms of over-testing, perhaps best exemplified by the "Choosing Wisely" campaign. ${ }^{1}$ Over-testing can be defined as the use of tests of unproven benefit or where the potential for harm exceeds the potential benefit. Several authorities have recommended that over-testing be monitored and used as a quality indicator for physicians. ${ }^{2-4}$ One example of over-testing is the case of a patient with limited life expectancy receiving a screening test for cancer. ${ }^{5-11}$ There is a lag between when a cancer is diagnosed by screening and when it would be diagnosed through symptoms, and a further lag before screening lowers the risk of death from the cancer. ${ }^{12}$ Thus, patients with limited life expectancy who undergo cancer screening are at risk of diagnosis and treatment of a cancer that would not otherwise have affected their health. ${ }^{8-10}$

Therefore, such "over-screening" could be used as a quality indicator, where physicians would be evaluated based on the percentage of patients with low life expectancy who are overscreened, similar to measuring the percentage with normal life expectancy who do not receive screening (under-screened). ${ }^{2-4}$

We have conducted preliminary work on developing quality measures for over-screening using Medicare data and estimating the life expectancy of individual patients. 9,11,13 However, individuals who are screened are healthier on average than those who are not screened-the so-called healthy user effect that is found with many tests and treatments. ${ }^{14}$ It is possible that these differences in health status are not completely captured by the data included in life expectancy algorithms, which in insurance claims data tend to rely on age, gender, and comorbidity. These algorithms would then underestimate the life expectancy of those who undergo cancer screening, and overestimate the life expectancy of those who do not. We explored this idea by estimating the life expectancy of older men and women as of $1 / 1 / 2003$ and comparing it to their actual survival. We hypothesized that men and women who had undergone prior cancer screening would have longer survival than what was estimated.

\section{METHODS}

We first identified a population of men and women as of 1/1/ 2003, and then conducted a look back to determine which 
patients had undergone prior screening mammography or PSA testing. This population was followed for 10 years $(1 / 1 / 2003$ to $12 / 31 / 2012$ ) to assess their survival. We compared the actual survival to their predicted life expectancy as of 1/1/ 2003, estimated with a validated algorithm for use with administrative data. We assessed whether a history of receiving cancer screening was associated with longer survival, independent of the characteristics used to predict life expectancy in the algorithm.

\section{DATA SOURCE}

The $5 \%$ Medicare claims data from 1999 to 2012 were used for the study. These files contain all claims for a $5 \%$ randomly selected sample of Medicare beneficiaries. The files used included 1) Medicare enrollment files, which include yearly information on patient demographics, monthly eligibility/ enrollment information, and vital status; 2 ) carrier files (claims for physician services); 3) outpatient statistical analysis files (claims for hospital outpatient visits); and 4) Medicare Provider Analysis and Review files (claims for hospital stays).

\section{STUDY POPULATION}

From the $5 \%$ Medicare claims data, we identified 543,970 women and 362,753 men who were 69-90 years old as of 1/1/ 2003. We used a cutoff age of 69 years to allow for a look-back period to assess prior receipt of cancer screening tests. To ensure that we had complete claims of these beneficiaries from which to identify screening utilization (mammography and PSA), we included those who had full coverage in Medicare Part A (hospital care) and Part B (physician and outpatient services) and had no health maintenance organization coverage during 1999-2003.

\section{OUTCOME VARIABLE: SURVIVAL}

Survival was tracked from 1/1/2003 through 12/31/2012 using the date of death field in the Medicare enrollment files.

\section{INDEPENDENT VARIABLES}

Recipient of Mammography Screening. For women in the cohort, we tracked claims for mammography screening during 2001-2002. We assessed mammography over 2 years, because some guidelines recommend screening every other year. A screening mammogram was identified as a bilateral mammogram (carrier files with Current Procedure Terminology [CPT] codes of 76091 and 76092) for a woman who had received no mammogram in the prior 11 months and with no breast-related diagnosis (International Classification of Diseases, Ninth Revision, Clinical Modification [ICD-9-
$\mathrm{CM}$ ] codes of $174 \mathrm{xx}, 2330$, or 61172 ) in the prior 2 years. ${ }^{15,16}$ We had previously validated the algorithm with mammography record review; $92 \%$ of the algorithm-identified screening mammograms were confirmed screenings. ${ }^{15}$

Recipient of PSA Screening. For men in the cohort, we tracked claims for PSA testing during 2002. A PSA screening was identified as a PSA test (carrier files with CPT code 84153 and Healthcare Common Procedural Coding System [HCPCS] code G0103) for a man who had no prostate-related diagnosis within the prior 3 years and no symptoms associated with prostate cancer (e.g., hematuria, weight loss, urinary obstruction) within the previous 3 months. ${ }^{17,18}$

Patient Characteristics. Data regarding age, sex, race/ethnicity (white, black, or other), Medicaid eligibility (yes/no), and the Elixhauser comorbidities ${ }^{19}$ were obtained from the Medicare files.

Estimation of Life Expectancy. We developed and validated gender-specific Cox proportional hazards models based on an individual's age and the presence or absence of any of the comorbidities included in the Elixhauser comorbidity measure. ${ }^{19}$ These comorbidities are listed in Table 3, plus the footnote to Table 3. The $\mathrm{C}$-statistics for the models predicting 10 -year mortality were 0.77 for men and 0.80 for women. ${ }^{13}$ In preliminary analyses we had included other factors, such as number of physician visits, but they did not improve the performance of the model. ${ }^{13}$ The method of estimating life expectancy was similar to others published around the same time $^{5}$ Other published methods include information on functional and emotional status, but these methods cannot be used with administrative data. ${ }^{6,8}$

\section{STATISTICAL ANALYSIS}

We conducted parallel analyses for women and men. In the text below, the term "screening" refers to screening mammography for women and PSA screening for men. Descriptive statistics were used to summarize screening use by subject characteristics. Using the age/comorbidity-based Cox proportional hazards model, we estimated each subject's life expectancy and categorized it as $<3,3-4,5-6,7-8$, or 9+ years as of $1 / 1 / 2003$. Kaplan-Meier survival curves were used to plot actual survival of subjects over the 10-year follow-up period, stratified by category of estimated life expectancy and prior screening use. ${ }^{20}$

We estimated the association between receipt of cancer screening and survival using three sets of analyses. First, we compared the hazard ratio estimate associated with prior receipt of screening with the estimates for different comorbidities using a multivariable Cox proportional hazards model, 
adjusting for age, race/ethnicity, and Medicaid eligibility. ${ }^{21}$ Second, we compared the reduction in $R^{2}$ associated with removing screening from the full model to the $R^{2}$ reduction associated with removing different comorbidities. Lastly, we calculated the percentage of individuals who had received screening who were then reclassified from the limited life expectancy group to the longer life expectancy group, after adding prior cancer screening history to the life expectancy prediction model.

We also conducted sensitivity analyses to determine whether any of the change in estimated life expectancy after adding prior cancer screening to the model was explained by changes in mortality from the cancer that was screened for. In those analyses we deleted any patients who had incident diagnoses of breast or prostate cancer during the screening period, and we censored patients when they developed incident breast or prostate cancer during the survival analysis period (20032012). We defined incident cancer as a new diagnosis (none in prior year) of breast or prostate cancer plus evidence of treatment (surgery, radiotherapy, chemotherapy, hormone therapy) as previously defined. ${ }^{22,23}$ This excluded 14,715 women with incident breast cancer and 15,245 men with incident prostate cancer.

We used Statistical Analysis System (SAS) version 9.2 software (SAS Institute Inc., Cary, NC) for data extraction and statistical analyses.

\section{RESULTS}

Table 1 summarizes the cohort characteristics and associated screening rates by gender. Factors associated with higher screening use (both mammography and PSA) included younger age, white race, ineligibility for Medicaid, and having 1-2 comorbid conditions. Screening rates increased with greater life expectancy. More than half $(52.1 \%)$ of women with an estimated 9+ years of life expectancy received screening mammograms, compared to $20.3 \%$ for those with $<3$ years of life expectancy. The screening rates for PSA were $28.9 \%$ for men with an estimated 9+ years of life expectancy vs. $15.9 \%$ for those with $<3$ years life expectancy.

Figure 1 presents survival curves from 2003 to 2012 for women (Fig. 1a) and men (Fig. 1b), stratified by their predicted life expectancy in 2003. The curves were further stratified by whether the subjects had received cancer screenings in 2001 or 2002 (for mammography) or in 2002 (for PSA). For each life expectancy group, the survival curve was higher for those who had undergone cancer screening than for those who had not. This is also shown in Table 2, which presents the observed median survival for women and men with different predicted years of life expectancy, stratified by whether they had undergone cancer screening. For example, in women with a predicted 7-8 years of life expectancy, the actual median survival was 8.1 years. After stratification by whether they had previously undergone mammography, those who had
Table 1. Cohort Characteristics by Gender and Screening Use

\begin{tabular}{|c|c|c|c|c|}
\hline \multirow[t]{2}{*}{ Parameter } & \multicolumn{2}{|l|}{ Women } & \multicolumn{2}{|l|}{ Men } \\
\hline & All & $\begin{array}{l}\text { \% Receiving } \\
\text { mammography } \\
\text { screening* }\end{array}$ & All & $\begin{array}{l}\% \\
\text { Receiving } \\
\text { PSA } \\
\text { screening* }\end{array}$ \\
\hline $\begin{array}{l}\text { No. of } \\
\text { patients }\end{array}$ & 543,970 & 43.9 & 362,753 & 25.6 \\
\hline \multicolumn{5}{|l|}{ Age (years) } \\
\hline $69-74$ & 183,802 & 53.5 & 145,427 & 29.2 \\
\hline $75-79$ & 154,554 & 47.8 & 107,627 & 26.2 \\
\hline $80-84$ & 121,645 & 38.1 & 71,658 & 21.9 \\
\hline $85-89$ & 83,968 & 23.9 & 38,041 & 17.6 \\
\hline \multicolumn{5}{|c|}{ Race/ethnicity } \\
\hline White & 481,466 & 45.0 & 324,619 & 26.4 \\
\hline Black & 40,888 & 36.3 & 22,809 & 16.8 \\
\hline Other & 21,615 & 33.0 & 15,325 & 21.9 \\
\hline \multicolumn{5}{|c|}{ Medicaid eligibility } \\
\hline No & 466,230 & 46.7 & 334,294 & 26.3 \\
\hline Yes & 77,739 & 27.3 & 28,459 & 18.2 \\
\hline \multicolumn{5}{|c|}{ No. of comorbidities } \\
\hline 0 & 152,303 & 40.9 & 121,930 & 21.0 \\
\hline $1-2$ & 146,586 & 50.5 & 88,165 & 31.8 \\
\hline 2 & 109,437 & 47.2 & 66,239 & 29.5 \\
\hline $3+$ & 135,643 & 37.3 & 86,419 & 23.0 \\
\hline \multicolumn{5}{|c|}{ Predicted life expectancy (years) } \\
\hline$<3$ & 24,722 & 20.3 & 23,552 & 15.9 \\
\hline $3-4$ & 47,541 & 26.0 & 42,229 & 20.3 \\
\hline $5-6$ & 74,254 & 32.1 & 58,415 & 23.2 \\
\hline $7-8$ & 80,108 & 40.3 & 65,133 & 26.2 \\
\hline $9+$ & 317,344 & 52.1 & 173,424 & 28.9 \\
\hline
\end{tabular}

* Receipt of a screening mammogram was assessed over a 2-year period, 2001-2002, because some authorities recommend every other year screening. Receipt of a screening PSA test was assessed in 2002

undergone screening had an actual median survival of 9.3 years, compared to 7.2 years for those who did not undergo screening mammography. With PSA screening in men, the effect was smaller but still substantial, with differences of greater than a year in median survival between the screened and unscreened groups.

We next compared the magnitude of impact on survival associated with receipt of cancer screening to the impact associated with selected comorbidities. Table 3 presents two Cox proportional hazards models, one for women and one for men. Each controls for age, race/ethnicity, poverty, and all the comorbidities listed in the table and footnotes. In women, lack of mammography screening was associated with a $52 \%$ increase in hazard of death $(\mathrm{HR}=1.52 ; 95 \% \mathrm{CI}: 1.51,1.54)$, comparable to a diagnosis of diabetes with complications ( $\mathrm{HR}=1.54 ; 95 \% \mathrm{CI}: 1.51,1.56)$, chronic obstructive pulmonary disease (COPD; HR $=1.53 ; 95 \% \mathrm{CI}: 1.51,1.54)$, and congestive heart failure $(\mathrm{CHF} ; \mathrm{HR}=1.51 ; 95 \% \mathrm{CI}: 1.49$, 1.53). Only four comorbidities (metastatic cancer, renal failure, lymphoma, and neurological disorders other than paralysis) had a stronger association with mortality than did mammography screening. In men, lack of PSA screening was associated with a hazard ratio of 1.23 (95\% CI: 1.22, 1.25), comparable to a diagnosis of uncomplicated diabetes $(\mathrm{HR}=$ $1.26 ; 95 \% \mathrm{CI}: 1.25,1.28)$ or liver disease ( $\mathrm{HR}=1.21: 95 \%$ CI: $1.16,1.26)$.

Another way of estimating the independent impact of a variable on an outcome is to assess the effect of removing that 


\section{a}

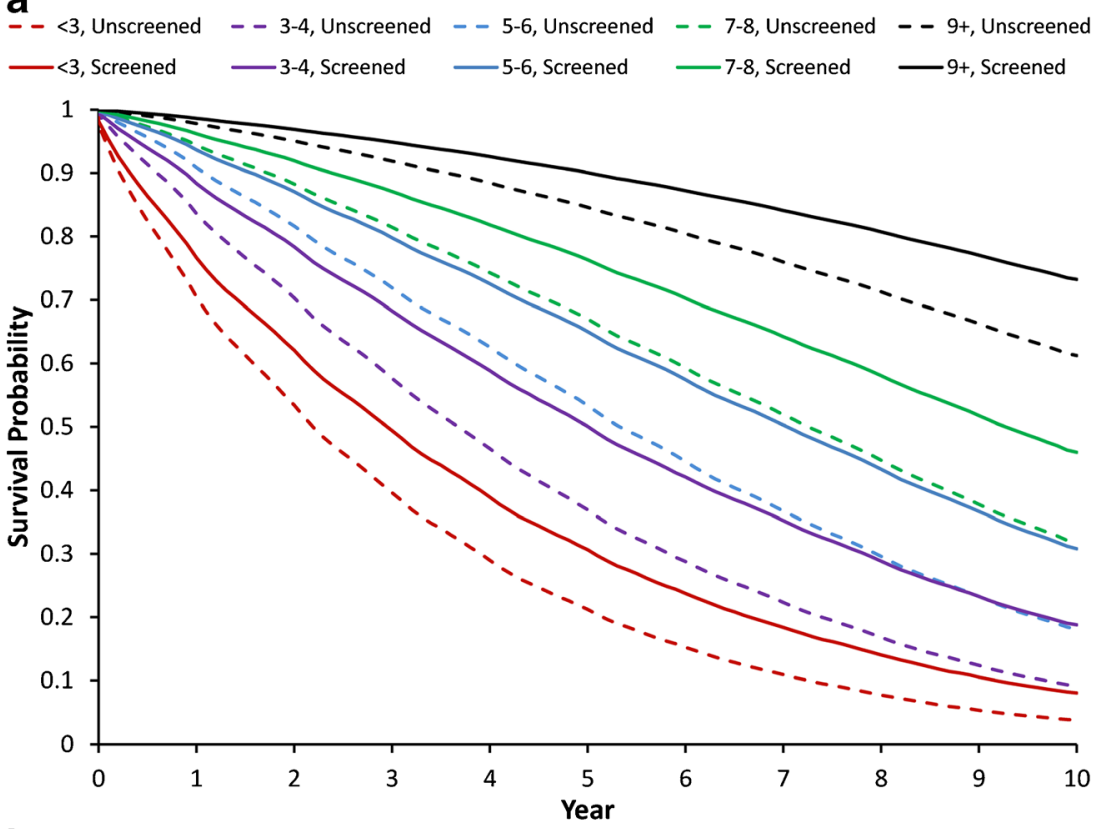

b

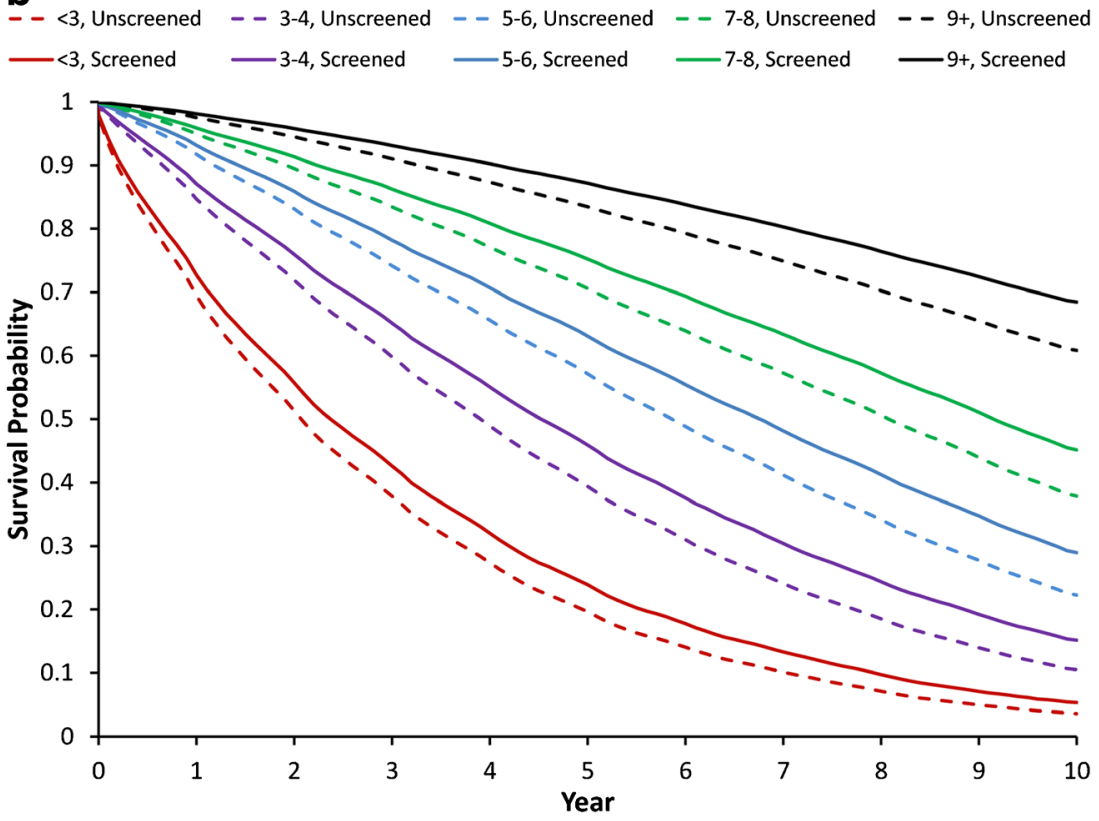

Figure 1 Actual survival among Medicare enrollees aged 69 to 90, stratified by whether they had received cancer screening and by estimated life expectancy, and adjusted for age, race, Medicaid eligibility, and comorbidities. a Screening mammography in women. b Screening PSA in men.

variable on the $R^{2}$ of the model. The $R^{2}$ explained by a variable relates both to the magnitude of the risk and to the prevalence of the variable in the population. The $R^{2}$ for the full survival model for women in Table 3 containing age, race/ethnicity, poverty, all comorbidities, and screening is 0.29 . Removing whether the patients received mammography reduces the $R^{2}$

Table 2. Median Survival for Each Life Expectancy Stratum, by Screening Use

\begin{tabular}{lllll}
\hline \hline Gender & Life expectancy (years) & \multicolumn{3}{l}{ Actual survival, median (interquartile range) } \\
\cline { 3 - 5 } & & All & Screened & Unscreened \\
\hline Female & $3-4$ & $4.0(1.8,7.1)$ & $5.3(2.7,8.7)$ & $3.6(1.6,6.5)$ \\
& $5-6$ & $5.9(3.0,9.4)$ & $7.3(4.1,>10)$ & $5.2(2.6,8.7)$ \\
Male & $7-8$ & $8.1(4.4,>10)$ & $9.3(5.6,>10)$ & $7.2(3.7,>10)$ \\
& $3-4$ & $4.0(1.9,7.1)$ & $4.8(2.3,7.9)$ & $3.9(1.8,6.8)$ \\
& $5-6$ & $6.1(3.1,9.8)$ & $6.9(3.8,>10)$ & $8.9(2.9,9.5)$ \\
& $7-8$ & $8.4(4.5,>10)$ & $9.2(5.3,>10)$ & $8.1(4.3,>10)$ \\
\hline
\end{tabular}


Table 3. Hazard of Death Associated with Screening Use, Compared to Comorbid Conditions, Adjusting for Age, Race/Ethnicity, and Medicaid Eligibility

\begin{tabular}{|c|c|c|c|c|c|c|}
\hline \multirow[t]{2}{*}{ Parameter } & \multicolumn{3}{|c|}{ Women } & \multicolumn{3}{|l|}{ Men } \\
\hline & $\%$ & HR & $(95 \%$ CI $)$ & $\%$ & HR & $(95 \% \mathrm{CI})$ \\
\hline \multicolumn{7}{|l|}{ Screening use } \\
\hline Unscreened & 56.12 & 1.52 & $(1.51,1.54)$ & 74.36 & 1.23 & $(1.22,1.25)$ \\
\hline \multicolumn{7}{|l|}{ Comorbidity* } \\
\hline Metastatic cancer & 0.85 & 3.00 & $(2.91,3.10)$ & 0.99 & 3.29 & $(3.18,3.41)$ \\
\hline Renal failure & 1.98 & 1.72 & $(1.68,1.76)$ & 2.98 & 1.61 & $(1.57,1.65)$ \\
\hline Lymphoma & 0.58 & 1.71 & $(1.64,1.78)$ & 0.72 & 1.65 & $(1.58,1.72)$ \\
\hline Neurological disorder & 3.26 & 1.64 & $(1.61,1.67)$ & 3.65 & 1.72 & $(1.69,1.76)$ \\
\hline AIDS & 0.00 & 1.56 & $(1.00,2.45)$ & 0.02 & 1.46 & $(1.11,1.93)$ \\
\hline Complicated diabetes & 3.87 & 1.54 & $(1.51,1.56)$ & 4.01 & 1.49 & $(1.46,1.52)$ \\
\hline COPD & 11.04 & 1.53 & $(1.51,1.54)$ & 12.56 & 1.57 & $(1.55,1.59)$ \\
\hline $\mathrm{CHF}$ & 9.16 & 1.51 & $(1.49,1.53)$ & 9.95 & 1.62 & $(1.59,1.64)$ \\
\hline Weight loss & 1.76 & 1.44 & $(1.41,1.47)$ & 1.40 & 1.47 & $(1.43,1.52)$ \\
\hline Psychosis & 1.48 & 1.43 & $(1.39,1.46)$ & 0.91 & 1.44 & $(1.39,1.50)$ \\
\hline Peripheral vascular disease & 7.25 & 1.33 & $(1.31,1.34)$ & 7.84 & 1.30 & $(1.28,1.32)$ \\
\hline Paralysis & 0.65 & 1.31 & $(1.26,1.36)$ & 0.69 & 1.27 & $(1.22,1.33)$ \\
\hline Uncomplicated diabetes & 13.53 & 1.31 & $(1.30,1.32)$ & 14.89 & 1.26 & $(1.25,1.28)$ \\
\hline Alcohol abuse & 0.23 & 1.30 & $(1.22,1.38)$ & 0.73 & 1.29 & $(1.23,1.35)$ \\
\hline Depression & 6.28 & 1.25 & $(1.24,1.27)$ & 3.38 & 1.26 & $(1.23,1.29)$ \\
\hline Cardiac arrhythmia & 12.42 & 1.23 & $(1.22,1.25)$ & 15.85 & 1.16 & $(1.15,1.18)$ \\
\hline Liver disease & 0.94 & 1.23 & $(1.19,1.27)$ & 0.95 & 1.21 & $(1.16,1.26)$ \\
\hline Rheumatoid arthritis & 3.71 & 1.21 & $(1.19,1.24)$ & 1.82 & 1.10 & $(1.07,1.13)$ \\
\hline Deficiency anemia & 4.15 & 1.17 & $(1.15,1.19)$ & 3.33 & 1.20 & $(1.18,1.23)$ \\
\hline
\end{tabular}

HR hazard ratio, CI confidence interval, AIDS acquired immune deficiency syndrome, COPD chronic obstructive pulmonary disease, CHF congestive heart failure

* All comorbidities were entered into two models, one for women and one for men, along with age, racelethnicity, and Medicaid eligibility. The comorbidities were sorted from high to low according to HR estimates for women. Comorbidities with HR $<1.2$ for both women and men were not listed. These included coagulopathy, fluid and electrolyte disorders, solid tumor w/o metastasis, drug abuse, chronic blood loss anemia, valvular disease, pulmonary circulation disease, hypertension, hypothyroidism, obesity, and peptic ulcer

by $4.8 \%$. In comparison, removing $\mathrm{CHF}$, metastatic cancer, or complicated diabetes from the model reduces the $R^{2}$ by $1.8 \%$ or less.

Table 4 shows the effect of adding prior screening behavior to reclassification of estimates of the number of the patients with $<7$ years (for women) and $<10$ years (for men) of life expectancy among those who had received screening. We chose 7 and 10 years because they are commonly used as cutoffs for when mammography and PSA testing might represent over-testing, respectively. Among screened women with estimated life expectancy of $<7$ years, $15.3 \%$ shifted to life expectancy of 7+ years after screening was added to the model. Among men with estimated life expectancy of $<10$ years who had been screened, $10.0 \%$ were reclassified as having $10+$ years after receipt of screening was added. We also looked at the magnitude of the shift in life expectancy when screening was added to the model. In screened women

Table 4. Reclassification of Life Expectancy Categories in Men and Women Who Had Received Screening, after Adding Prior Cancer Screening History to Estimates of Life Expectancy

\begin{tabular}{|c|c|c|}
\hline $\begin{array}{l}\text { Estimated survival in the model } \\
\text { without screening }\end{array}$ & \multicolumn{2}{|c|}{$\begin{array}{l}\text { Number }(\%) \text { of patients } \\
\text { reclassified }\end{array}$} \\
\hline \multirow{3}{*}{ Women with $<7$ years $(n=40,901)$} & No change & Shift to $7+$ \\
\hline & $\begin{array}{l}34,638 \\
(84.79)\end{array}$ & $6263(15.3)$ \\
\hline & No change & $\begin{array}{l}\text { Shift to } 10+ \\
\text { years }\end{array}$ \\
\hline Men with $<10$ years $(n=51,023)$ & $45,894(90)$ & $5129(10.0)$ \\
\hline
\end{tabular}

with estimated life expectancy of $<7$ years, $99 \%$ had an increase in estimated life expectancy of $\leq 2$ years when screening was added to the model. For men with life expectancy of $<10$ years, no increase greater than 1 year was found by adding receipt of screening.

Finally, we conducted sensitivity analyses to determine whether the increase in survival associated with receipt of mammography or PSA screening was due in part to a reduction in deaths from those two cancers. We did this by excluding from the sample subjects with a diagnosis of and treatment for those cancers during the period in which we assessed receipt of cancer screening, and by censoring any patients in the Cox proportional hazards survival analysis when they were diagnosed with and treated for breast or prostate cancer. This had almost no effect on the findings. For example, in the survival analyses presented in Table 3 , eliminating those with incident breast cancer changed the hazard ratio associated with prior receipt of screening mammography from 1.53 to 1.55 , while eliminating those with prostate cancer did not change the hazard ratio (1.23) associated with receipt of PSA screening.

\section{DISCUSSION}

In this study, we found that the decision to undergo screening for cancer was a powerful predictor of life expectancy. It is important to emphasize that the cancer screening itself is not the cause of this increase. While randomized trials of breast 
and prostate cancer have found reductions in cancer deaths, no changes were found in overall mortality with screening. ${ }^{24,25}$ We also addressed this question directly in sensitivity analyses by deleting patients with new cancer diagnoses, and found no change in the magnitude of the association between receipt of cancer screening and survival. Thus, the association of these cancer screening tests with increased life expectancy must stem from selection of healthier patients into the screened group.

Why does receipt of cancer screening predict life expectancy, even after controlling for comorbidity? There is considerable information available to physicians and their patients on factors that affect life expectancy that is not captured or is incompletely captured in administrative claims data. These include functional status, cognitive status, emotional status, social support, and severity of disease. ${ }^{26}$ For example, one of the strongest independent predictors of survival is how individuals rate their health on an excellent/good/fair/poor scale. ${ }^{27}$ This remains a strong predictor after controlling for comorbidity, functional and cognitive status, and a number of physiologic variables. ${ }^{26}$ Clearly, factors such as self-rated health and functional status are knowable by patients and their physicians, and would be expected to influence medical decisions such as receipt of cancer screening.

Life expectancy can be an important factor in assessing the need for preventive services and medical treatments in the elderly. For example, the American Cancer Society and the American Urological Association both discourage PSA screening in men with life expectancy of less than 10 years, ${ }^{28,29}$ while the American Cancer Society and U.S. Preventive Services Task Force advocate consideration of life expectancy in decisions about mammography screening. ${ }^{28,30}$

Receipt of cancer screening by those with limited life expectancy can be used as a quality measure, and physicians could be assessed by the proportion of their patients with limited life expectancy who receive screenings, just as they are currently assessed by the proportion of their patients who do not receive screenings. ${ }^{2-4,9}$ The results of this paper add a layer of complexity to that concept. Within any stratum of estimated life expectancy, those who had received screening had longer actual survival then those who did not. Therefore, the method of estimating median life expectancy underestimated the actual survival of the population who received screening, which moved some of them from an "over-screening" to an "appropriate screening" group. This complicates attempts to develop quality metrics for overuse of screening based on administrative data, although it does not preclude them. The percentage of patients who shifted out of the limited life expectancy category was modest, $15 \%$ for women and $10 \%$ for men. Also, the increases in estimated life expectancy associated with receipt of screening were of relatively small magnitude: 2 years or less in women and 1 year or less in men. That means that any error in estimating those with limited life expectancy who received screenings could be avoided by lowering the cut point for "limited life expectancy" by 1 or 2 years.
The current study does have some limitations. Screening behavior was assessed in a single 1- or 2-year period. The observed selection bias may be even stronger when comparing those receiving regular repeated screening to those who do not. Also, we were unable to determine cause of death to isolate deaths from breast or prostate cancer vs. mortality from other causes. We addressed this issue in sensitivity analyses by removing all patients with incident breast or prostate cancer during the screening period and the 10 year-survival period. This had no effect on the results. Finally, it is possible that life expectancy measures other than the one employed might be less likely to show selection bias by screening behavior. ${ }^{31}$

In summary, cancer screening behavior was a strong predictor of life expectancy, independent of comorbidity and other variables included in an algorithm for estimating life expectancy from administrative data. This means that patients and physicians are making somewhat more appropriate choices about screening than are indicated by the method for estimating life expectancy from administrative data.

Contributors: JSG: design of the work, acquisition and interpretation of data, drafting and critical revision of the work; KS: analysis and interpretation; critical revision of the work; SL: analysis and interpretation; critical revision of the work; AT: analysis and interpretation; critical revision of the work. All authors had access to the data and have read and approved the final version of the paper for publication, and all agree to be accountable for all aspects of the work in ensuring that questions related to the accuracy or integrity of any part of the work are appropriately investigated and resolved.

Corresponding Author: James S. Goodwin, MD; Sealy Center on AgingUniversity of Texas Medical Branch, 301 University Blvd, Galveston, TX 77555-0177, USA (e-mail: jsgoodwi@utmb.edu).

\section{Compliance with Ethical Standards:}

Funders: This work was supported by grants from the National Institutes of Health (P3O-AG024832, UL1TR000071 and KO5 CA 134923), the Agency for Healthcare Research and Quality (R24HSO22134), and the Cancer Prevention Research Institute of Texas (RP101207). The sponsors played no role in the acquisition, analysis, or interpretation of data, or in determining where to send the manuscript for publication.

\section{Prior Presentations: None.}

Conflict of Interest: The authors declare that they do not have a conflict of interest.

\section{REFERENCES}

1. Cassel CK, Guest JA. Choosing wisely. Helping physicians and patients make smart decisions about their care. JAMA. 2012;307(17):1801-2.

2. Lee SJ, Walter LC. Quality indicators for older adults: preventing unintended harms. JAMA. 2011;306:1481-2.

3. Mathias JS, Baker DW. Developing quality measures to address overuse. JAMA. 2013;309:1897-8.

4. Schwartz AL, Landon BE, Elshaug AG, Chernew ME, McWilliams JM. Measuring low-value care in medicare. JAMA Int Med. 2014;174:1067-76.

5. Cho C, Klabunde CN, Yabroff $\mathbf{K R}$, et al. Comorbidity-adjusted life expectancy: a new tool to inform recommendations for optimal screening strategies. Ann Intern Med. 2013;159:667-76.

6. Schonberg MA, Breslau ES, McCarthy EP. Targeting of mammography screening according to life expectancy in women aged 75 and older. J Am Geriatr Soc. 2013;61:388-95.

7. Gross CP, McAvay, Krumholz, Paltiel D, Bhasin D, Tinetti ME. The effect of age and chronic illness on life expectancy after a diagnosis of 
colorectal cancer: implications for screening. Ann Intern Med. 2006; 145:646-53.

8. Royce TJ, Hendrix LH, Stokes WA, Allen IM, Chen RC. Cancer screening rates in individuals with different life expectancies. JAMA Int Med. 2014;174:1558-65.

9. Tan A, Kuo YF, Elting LS, Goodwin JS. Refining physician quality indicators for screening mammography in older women: distinguishing appropriate use from overuse. J Am Geriatri Soc. 2013;61:380-7.

10. Walter LC, Covinsky KE. Cancer screening in elderly patients: a framework for individualized decision making. JAMA. 2001;285:2750-6.

11. Mittal S, Lin Y, Tan A, Kuo YF, El-Serag HB, Goodwin JS. Limited life expectancy among a subgroup of Medicare beneficiaries receiving screening colonoscopies. Clin Gastroenterol Hepatol. 2014;12:443-50.e.1.

12. Lee SJ, Leipzig RM, Walter LC. Incorporating lag time to benefit into prevention decisions for older adults. JAMA. 2013;310:2609-10.

13. Tan A, Kuo Y, Goodwin JS. Predicting life expectancy for community dwelling older adults using Medicare claims data. Am J Epidemiol. 2013;178:974-83.

14. Koya DL, Chen JG, Smith TG, Moran WP. Screening mammography use in medicare beneficiaries reflects 4-year mortality risk. Am J Med. 2011;124:369.e1-8.

15. Freeman JL, Zhang D, Freeman DH, Goodwin JS. An approach to identifying incident breast cancer cases using medicare claims data. J Clin Epidemiol. 2000;53:605-14.

16. Randolph WM, Mahnken JD, Goodwin JS, Freeman JL. Using medicare data to estimate the prevalence of breast cancer screening in older women: comparison of different methods to identify screening mammograms. Health Serv Res. 2002;37:1643-57.

17. Walter LC, Bertenthal D, Lindquist $\mathbf{K}$, Konety BR. PSA screening among elderly men with limited life expectancies. JAMA. 2006;296:2336-42.

18. Jaramillo E, Tan A, Yang L, Kuo YF, Goodwin JS. Variation among primary care physicians in prostate-specific antigen screening of older men. JAMA. 2013;310:1622-4.
19. Quan H, Sundararajan V, Halfon $\mathbf{P}$, et al. Coding algorithms for defining comorbidities in ICD-9-CM and ICD-10 administrative data. Med Care. 2005;43:1130-9.

20. Kaplan EL, Meier P. Nonparametric estimation from incomplete observations. J Am Stat Assoc. 1958;5:457-81.

21. Cox DR. Regression models and life-tables. In: Kotz S, Johnson N, eds. Breakthroughs in Statistics. New York: Springer; 1992:527-41.

22. Giordano SH, Lin YL, Kuo YF, Hortobagyi GN, Goodwin JS. Decline in the use of anthracyclines for breast cancer. J Clin Oncol. 2012;30:2232-39.

23. Goodwin JS, Jaramillo E, Yang L, Kuo YF, Tan A. Is anyone listening? Variation in PSA screening among providers for men 75+ before and after United States Preventive Services Task Force recommendations against it: a retrospective cohort study. PLOS One. 2014;9:e107352.

24. Gotzsche PC, Jorgensen KJ. Screening for breast cancer with mammography. Cochrane Database Syst Rev. 2013;6:CD001877.

25. Dragan I, O'Connor D, Green S, Wilt TJ. Screening for prostate cancer: an updated Cochrane systematic review. BMJ Intl. 2015;107:882-91.

26. Fried LP, Kronmal RA, Newman AB, et al. Risk factors for 5-year mortality in older adults: the Cardiovascular Health Study. JAMA. 1998;279:585-92.

27. Schoenfeld DE, Malmrose LC, Blazer DG, Gold DT, Seeman TE. Selfrelated health and mortality in the high functioning elderly-a closer look at healthy individuals: MacArthur field study of successful aging. J Gerontol Med Sci. 1994;49:M109-15.

28. Smith RA, Cokkinides V, Brawley Ow. Cancer screening in the United States, 2012: a review of current American Cancer Society guidelines and current issues in cancer screening. CA Cancer J. 2012;62:129-42.

29. Carter HB, Albertson PC, Barry MJ, et al. Early detection of prostate cancer: AUA Guideline. J Urol. 2013;190:419-26.

30. U.S. Preventive Services Task Force. Screening for breast cancer: recommendations and rationale. Ann Intern Med. 2002;137(5 Part 1):344-6.

31. Yourman LC, Lee SJ, Schonberg MA, Widera EW, Smith AK. Prognostic indices for older adults: a systematic review. JAMA. 2012;307:182-92. 